\title{
Welcome to volume 13 of Future Medicinal Chemistry
}

\author{
Harriet Wall*,1 \\ ${ }^{1}$ Future Science Group, Unitec House, 2 Albert Place, London, N3 1QB, UK \\ *Author for correspondence: h.wall@future-science.com
}
'We appreciate the support and engagement that has been provided over the past year and look forward to what is to come in 2021."

First draft submitted: 4 November 2020; Accepted for publication: 4 November 2020; Published online: 4 December 2020

Keywords: drug design • Future Medicinal Chemistry • research • top content

Welcome to volume 13 of Future Medicinal Chemistry! We'd like to take this opportunity to discuss the highlights seen last year as well as what we can expect in 2021. We are grateful to our editorial board members, authors, peer reviewers and readers, and we look forward to continuing to work with all of our contributors again in 2021.

\section{Coronavirus disease 2019}

It goes without saying that 2020 has been an unprecedented year. The outbreak of coronavirus disease 2019 (COVID-19) has challenged the scientific community greatly, putting lives at risk and research on hold and obstructing education.

During these extraordinary circumstances, it has become clear that medicinal chemistry is essential for the development of drugs targeting the virus. Over the course of 2020, the journal has published some high-impact articles concerning COVID-19, all of which have been made available to read for free. Notably, 'Tackling SARS$\mathrm{CoV}-2$ : proposed targets and repurposed drugs' reviewed the virus's druggable targets and potential avenues for drug repurposing [1]. In addition, 'Evidence supporting the use of peptides and peptidomimetics as potential SARS-CoV-2 (COVID-19) therapeutics' discussed novel peptide-based therapeutics that could potentially target the virus's entry mechanism [2].

\section{Early career research}

In 2020, we created our Early Career Panel, formed of researchers in the first ten years of their career [3]. Now more than ever, it is important to invest in the development of medicinal chemistry and bridge the gap across generations within the field. We are excited to announce our upcoming Early Career Special Focus Issue, consisting of articles exclusively from members of the panel that will cover a wide range of exciting topics.

\section{Content highlights of $\mathbf{2 0 2 0}$}

Our most read article this year, 'Assays and technologies for developing proteolysis targeting chimera degraders,' discussed the landscape of available assays to evaluate proteolysis targeting chimera substrate degradation [4]. Choosing the right assay for characterizing a proteolysis targeting chimera is essential for medicinal chemists to understand the mechanism of action of a proteolysis targeting chimera molecule, making assay development a key asset to this field.

In addition to this, a wide range of review style articles were published in 2020 that aimed to highlight recent significant advances in research, ongoing challenges and unmet needs. Of note, 'Proton-sensing G protein-coupled receptors: detectors of tumor acidosis and candidate drug targets' was particularly popular among our readers [5]. This review focused on psGPCR expression in the tumor microenvironment and discussed the subsequent identification of new therapeutics for the treatment of a variety of cancers. 

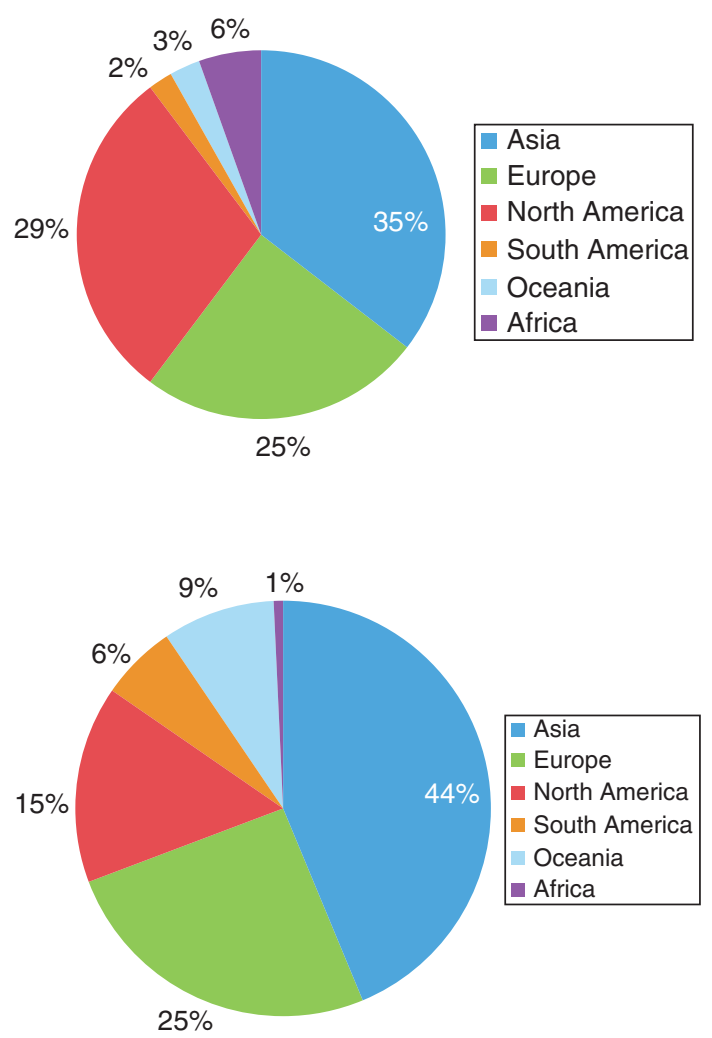

Figure 1. Percentage readership by geographic location.

Figure 2. Percentage authorship by geographic location.

Primary research plays an essential role in the development of medicinal chemistry. Many research articles were published in Future Medicinal Chemistry last year that continue to be popular among our readers. Highlights include 'Pathway and mechanism of drug binding to chemokine receptors revealed by accelerated molecular simulations,' '3-amino-alkylated indoles: unexplored green products acting as anti-inflammatory agents' and 'Radiolabeling of [11C]FPS-ZM1, a receptor for advanced glycation end products-targeting positron emission tomography radiotracer, using a [11C]CO2-to-[11C]CO chemical conversion' [6-8].

In addition to our core content of reviews, perspectives and original research, the journal also featured content on topical areas of debate relevant to academia and industry, including editorials, commentaries and special reports. Zhang et al., University of Florida, Florida, USA, highlighted methods for targeting the apoptotic pathway in cancer therapy, with a focus on BCL-2 family proteins, in their editorial titled 'Targeting anti-apoptotic BCL-2 family proteins for cancer treatment' [9]. Additionally, Wiederkehr and Santo-Domingo, Nestlé Research, Vaud, Switzerland, discussed the development of next-generation type 2 diabetes drugs in the popular editorial 'Targeting mitochondrial ion channels in type 2 diabetes' [10].

Last year, Future Medicinal Chemistry's senior editorial board member, Jonathan Baell, Monash University, Melbourne, Australia, co-authored a special report titled 'Action plan for hit identification (APHID): KAT6A as a case study,' discussing a novel method for optimizing high-throughput screening [11]. In addition, Kessler et al. from Boehringer Ingelheim, Vienna, Austria, explored advances in targeting the three human $R A S$ genes, KRAS, $N R A S$ and HRAS, for the treatment of cancer in the popular special report titled 'Drugging all RAS isoforms with one pocket' [12].

\section{Demographics}

Future Medicinal Chemistry has seen a continued increase in readership over the past year, with the majority of readers based in Asia, followed by North America and Europe (Figure 1).

Future Medicinal Chemistry continues to receive submissions from around the globe. The authorship demographics largely reflect that of our readership, with the majority of authors submitting from institutions in Asia, Europe and North America (Figure 2). 


\section{Article outreach \& online presence}

Future Medicinal Chemistry continues to be active across social media, and we are keen for our readers to engage. Follow us on Twitter at @fsgfmc and on LinkedIn to stay updated regarding our latest content, including our journal highlights and the latest medicinal chemistry news [13,14].

\section{Conclusion}

We appreciate the support and engagement that has been provided over the past year and look forward to what is to come in 2021. As always, we are happy to receive any unsolicited articles to the journal, whether they are original research, reviews or opinion pieces. If you have a submission that you would like us to consider, you can find details on article preparation and submission online [15]. Finally, we would like to thank everyone for their continued feedback and support. We look forward to working with all of you over the coming year.

\section{Financial \& competing interests disclosure}

$\mathrm{H}$ Wall is an employee of Future Science Ltd. The author has no other relevant affiliations or financial involvement with any organization or entity with a financial interest in or financial conflict with the subject matter or materials discussed in the manuscript apart from those disclosed.

No writing assistance was utilized in the production of this manuscript.

\section{References}

1. Joshi S, Joshi M, Degani MS. Tackling SARS-CoV-2: proposed targets and repurposed drugs. Future Med. Chem. 12(17), 1579-1601 (2020).

2. VanPatten S, He M, Altiti A et al. Evidence supporting the use of peptides and peptidomimetics as potential SARS-CoV-2 (COVID-19) therapeutics. Future Med. Chem. 12(18), 1647-1656 (2020).

3. Future Medicinal Chemistry Early Career Panel. https://www.future-science.com/journals/fmc/earlycareerpanel

4. Liu X, Zhang X, Lv D et al. Assays and technologies for developing proteolysis targeting chimera degraders. Future Med. Chem. 12(12), 1155-1179 (2020).

5. Insel PA, Sriram K, Salmerón C et al. Proton-sensing G protein-coupled receptors: detectors of tumor acidosis and candidate drug targets. Future Med. Chem. 12(6), 523-532 (2020).

6. Pawnikar S, Miao Y. Pathway and mechanism of drug binding to chemokine receptors revealed by accelerated molecular simulations. Future Med. Chem. 12(13), 1213-1225 (2020).

7. Mazzotta S, Frattaruolo L, Brindisi $\mathrm{M}$ et al. 3-amino-alkylated indoles: unexplored green products acting as anti-inflammatory agents. Future Med. Chem. 12(1), 5-17 (2020).

8. Luzi F, Savickas V, Taddei C et al. Radiolabeling of [11C]FPS-ZM1, a receptor for advanced glycation end products-targeting positron emission tomography radiotracer, using a [11C]CO2-to-[11C]CO chemical conversion. Future Med. Chem. 12(6), 511-521 (2020).

9. Zhang X, Liu X, Zhou D. Targeting anti-apoptotic BCL-2 family proteins for cancer treatment. Future Med. Chem. 12(7), 563-565 (2020).

10. Wiederkehr A, Santo-Domingo J. Targeting mitochondrial ion channels in type 2 diabetes. Future Med. Chem. 12(17), 1525-1527 (2020).

11. Yi X, Xue L, Thomas T, Baell JB. Action plan for hit identification (APHID): KAT6A as a case study. Future Med. Chem. 12(5), 423-437 (2020).

12. Kessler D, Bergner A, Böttcher J et al. Drugging all RAS isoforms with one pocket. Future Med. Chem. doi:10.4155/fmc-2020-0221 (2020) (Epub ahead of print).

13. Future Medicinal Chemistry. Twitter page (2020). www.twitter.com/fsgfmc

14. Future Medicinal Chemistry. LinkedIn group (2020). www.linkedin.com/groups/2822505

15. Future Medicinal Chemistry2020www.future-science.com/loi/fmc 
